Open Access

\title{
A framework of fuzzy integrated MADM and GMA for maintenance strategy selection based on agile enabler attributes
}

Priyank Srivastava ${ }^{1,2^{*}}$, Dinesh Khanduja ${ }^{1}$ and V.P. Agrawal ${ }^{3}$

\author{
* Correspondence: \\ priyanksrivastava_me@yahoo.in; \\ psrivastava5@amity.edu \\ ${ }^{1}$ Department of Mechanical \\ Engineering, NIT, Kurukshetra, \\ Haryana 136119, India \\ ${ }^{2}$ Department of Mechanical \\ Engineering, ASET, AUUP, Noida, UP \\ 201303, India \\ Full list of author information is \\ available at the end of the article
}

\begin{abstract}
Background: Maintenance cost of machinery, equipment and tooling are main contributor to total cost of production in processing industry. The aim of study is to explore selection of optimum maintenance strategy for steam generating unit (SGU) in a coal fired thermal power plant using various MADM and graphical approach. The novelty of research work is selection of strategy based on agile enabler attributes and use of graphical approaches for decision making. This selection procedure allows for speedy conflux of large number of attributes, which gives the decision maker an effective tool select optimum strategy.

Case description: The practicality of the framework has been justified through implementation in thermal power plant, situated in northern part of India. The plant has total installed capacity of $2400 \mathrm{MW}$. It has eight units. The present study is done in unit number 8 .
\end{abstract}

Discussion and evaluation: This selection is based on agile enabler attributes. Triangular fuzzy number (TFN) is used to take care of imprecise and vague judgements. For ranking of maintenance strategies MADM approaches of fuzzy AHP (FAHP), fuzzy TOPSIS (FTOPSIS); and Graphical approaches of Line graph and spider graph are used, respectively.

Conclusion: PDM has been ranked first by all evaluating approaches. There is also synergy in results. The proposed work not only provides the best alternative but also alternative ranking. The results will be shared with management for implementation so as to increase system availability and reduce operation cost.

Keywords: Maintenance strategy, Agile capabilities/enablers attributes, TFN, MADM, FAHP, FTOPSIS, Line graph, Spider graph, Thermal power plant

\section{Introduction and Research review}

Maintenance cost is one of the main expenditure items for the firm, which can reach $15-70 \%$ of production costs, varying according to the type of industry [39]. A huge amount (about 600 billion dollars) of money was spent on maintenance for a selected group of industries in USA ([37]; Chan et al. [10]). One third of all maintenance cost is wasted as a result of unnecessary or improper maintenance activities [20]. Contrary, less maintenance, will results in less maintenance cost but has to face more changes with machine breakdown. Therefore, optimal

(c) The Author(s). 2017 Open Access This article is distributed under the terms of the Creative Commons Attribution 4.0 International License (http://creativecommons.org/licenses/by/4.0/), which permits unrestricted use, distribution, and reproduction in any medium, provided you give appropriate credit to the original author(s) and the source, provide a link to the Creative Commons license, and indicate if changes were made. 
maintenance policy will be helpful in solving this problem [38]. An efficient maintenance can improve the availability, product quality, safety level and reliability of the equipment. Now the role of maintenance is changing from a necessary evil to a profit contributor. It has become partner of companies to achieve the world class competitiveness [34]. The selection of the best maintenance strategy for each of equipment is important for every manufacturing firm $[3,4,21,28,39]$. The selection of best maintenance strategy for different machines in any industry is one of the most important problems. It calls for considering many maintenance goals or criteria because each equipment or machine in the plant has different operating parameters, different levels of safety and reliability requirements respectively [36]. Considering the reviewed literature it is apparent that selection of optimum maintenance strategy needs consideration of various criteria and is essentially a multi criteria decision making problem.

There have been studies on selection of an optimum maintenance policy. Bevilacqua and Braglia [6] presented a multi-criteria decision making (MCDM) model for the selection of the optimal maintenance policy in an Italian oil refinery processing plant. Shahin et al. [26] used ANP for maintenance policy selection according to reliability, availability, maintainability and cost of maintenance in a mining industry. Shahin et al. [27] used decision making grid, sigma level, and process capability index for determining appropriate maintenance strategy in steel industry. Khorasani and Bafruei [15] applied fuzzy AHP approach for evaluating and selecting the best supplier in a pharmaceutical industry. Unlike many other decision theories (such as most inventory and scheduling models, linear programming, dynamic programming, etc.), MCDM methodologies are controversial and there is not an unique theory accepted by everyone in the field [33].

There are studies on use of integrated models for selection of alternatives. Sharma et al. [28] used fuzzy linguistic modelling with MISO model for maintenance strategy selection of paper plant. Shyjith et al. [29] developed a model using AHP and TOPSIS for maintenance selection in textile industry and then Ilangkumaran and Kumanan [14] integrated fuzzy AHP and TOPSIS algorithm to select the maintenance policy for textile industry. Pourjavad et al. [23] used ANP and TOPSIS for maintenance policy selection in mining industry. The main aim of study was to recommend an efficient method to determine the most suitable maintenance strategy. Ding et al. [12] developed a model for optimal maintenance policy selection in palm oil industry. The best alternative was selected by integration of failure modes and effect analysis (FMEA) and technique for order preference by similarity to ideal solution (TOPSIS) respectively. Panchal and Kumar [22] proposed integrated fuzzy failure mode and effect analysis (FMEA) model for assessing critical components of a power producing unit of thermal power plant.

When choosing a maintenance method, we have to consider different attributes. Some attributes like cost (hardware and software), training expenses, equipment reliability, TBF (time between failure) are quantitative in nature. Whereas safety, flexibility, acceptability etc. are qualitative in nature and are subjected to fuzziness or uncertainty. Srivastava et al. [31] integrated agile thinking with maintenance policy in thermal power plant. The agile manufacturing (AGM) concept became popular in the year 1991. The four key dimensions of agile manufacturing system [16] and its enabling subsystems [30] have been shown in Fig. 1. 

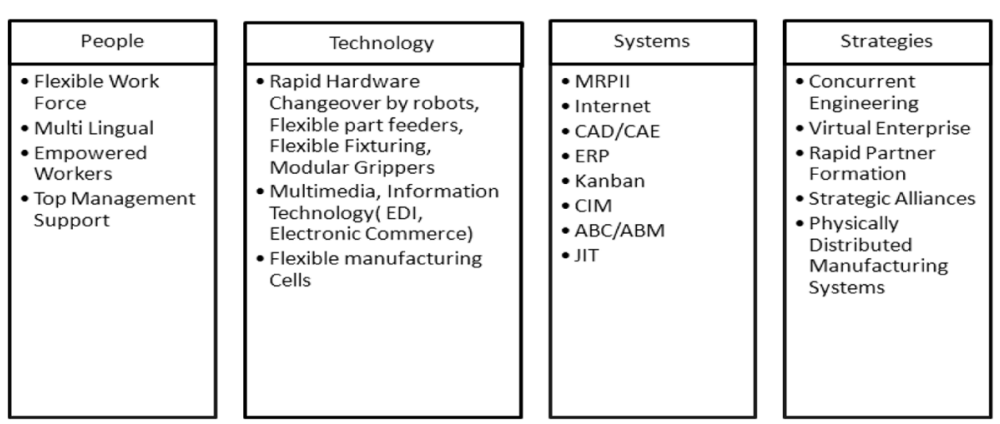

Fig. 1 System and sub-systems of AGM

Bhangale et al. [7] used graphical approach for attributes based selection of robot. Rao and Baral [24] applied graphical approach for selection of feedstock for anaerobic digestion. Al-Najjar [1] suggested (i) a graphical method for selection of cost effective monitoring technique, (ii) a graphical method to estimate the level at which equipment should be replaced depending upon threshold value. Both of these methods were based on concept of Total time on test, TTT plots. Many qualitative factors are included in this study. It is evident from literature review that FAHP and FTOPSIS approaches have been widely used in such processes. Both methods are easy to understand and compute. FAHP is a flexible decision approach. On other hand FTOPSIS enables decision maker to grasp the fuzzy logic influence of one critera over other. The graphical methods of line and spider graph methods are easy to calculate, visualize, and provide a simplistic approach for comparison, ranking of alternatives.

The literature reviewed by author reveals that, (i) There are less or practically no inference of maintenance strategy selection based on agile maintenance enabler attributes, (ii) There are less inferences of application of Graphical methods for selection of maintenance alternatives of SGU in thermal power plant, (iii) Fuzziness is not included in graphical methods. To fill this gap author proposes to demonstrate and evaluate maintenance strategies using fuzzy AHP, fuzzy Topsis and graphical method for steam generating unit of coal fired thermal plant. This selection is based on agile enabler attributes. The agile enabler attributes are those elements that increase agility of any system under study. The attributes or subsystem of the same is shown in Fig. 1. This study will be helpful for the manager to select the best maintenance strategy as well as to solve other MCDM problem.

\section{Research objective and Methodology}

For determining optimal maintenance strategy fuzzy AHP, fuzzy Topsis and graphical methods of line graph and spider graph have been used by the author. Four important criteria (i) Safety, (ii) Cost, (iii) Value Added, (iv) Execution Capability, and subsequently eleven sub-criteria (section "Maintenance strategy attributes and alternatives") have been considered for maintenance decision making for system under study. Five alternative strategies (i) Corrective Maintenance (CM), (ii) Preventive Maintenance (PM), (iii) Condition Based Maintenance (CBM), (iv) Predictive Maintenance (PDM) and (v) Opportunistic Maintenance (OP) have been 
finalized for analysis. TFN have been used to overcome imprecise and vague judgement of experts. For computing weights for fuzzy AHP and fuzzy TOPSIS, fuzzy extent analysis method has been used. The weighted normalized fuzzy decision matrix of fuzzy TOPSIS has been used to develop line graph and spider graph methods. The procedural flow chart is shown in Fig. 2. Using this methodology research objective of:

i. Ranking of different alternatives using fuzzy AHP

ii. Ranking of different alternatives using fuzzy TOPSIS

iii. Ranking of different alternatives using graphical method

iv. Comparison of results

v. Prioritizations of attributes

vi. Analysing and discussing limitations and future scope has been addressed.

It is evident from Fig. 1 that key dimensions of AGM i.e. people, strategy; system and technology along with enabling subsystems have synergy with criteria and sub-criteria selected for present study. Therefore research objective of ranking alternatives by different approaches addressed is based on agile enabler attributes.

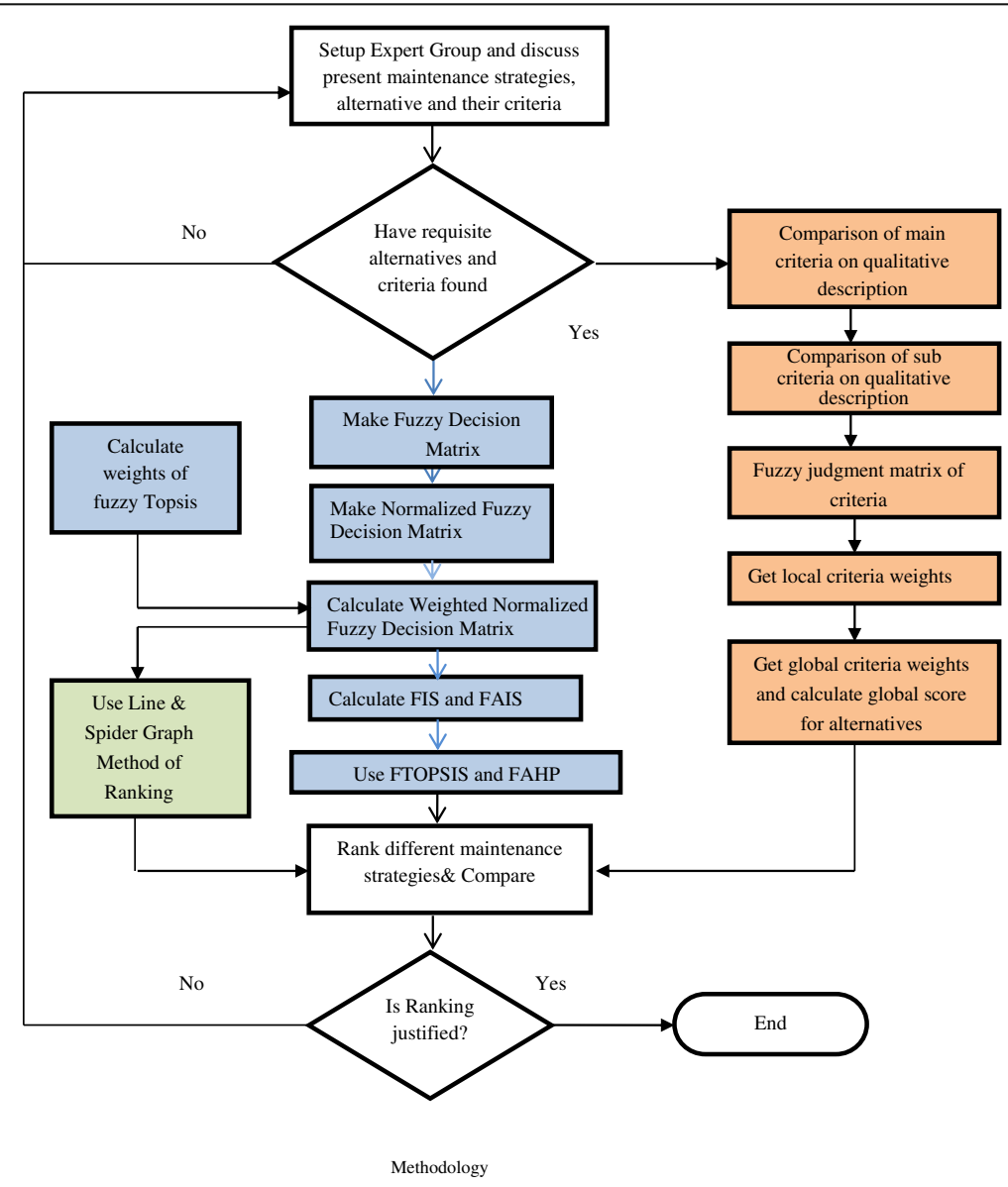

Fig. 2 Methodology 


\section{Maintenance strategy attributes and alternatives Maintenance attributes}

Different industries may have different maintenance goals. From the expert's opinion these goals can be divided into the following four aspects [19, 36, 39]. These aspects are:

a) Aspect I (Safety): Safety levels required are often high in many manufacturing concerns, especially in chemical industry and power plants. The relevant factors describing the safety are:

$\triangleright$ Environment $\left(\mathrm{SCR}_{1}\right)$ : The failure of equipment with poisonous liquid or gas can pollute the environment.

$>$ Personnel $\left(\mathrm{SCR}_{2}\right)$ : The failure of machines can lead to serious damage of personnel on site, such as high pressure vessels in chemical plants.

$\triangleright$ Equipment Safety $\left(\mathrm{SCR}_{3}\right)$ : Equipment safety is a major concern in process industry. For example, the sudden breakdown of a water-feeding pump can result in serious damage of the corresponding boiler in a power plant.

b) Aspect II (Cost): Different maintenance strategies have different expenditures on hardware, software and personnel training.

$\triangleright$ Hardware $\left(\mathrm{SCR}_{4}\right)$ : For condition-based maintenance and predictive maintenance, a number of sensors and some computers are indispensable.

$\triangleright$ Software $\left(\mathrm{SCR}_{5}\right)$ : Software is needed for analysing measured parameters data when using condition- based maintenance and predictive Maintenance strategies.

$\triangleright$ Personnel Training $\left(\mathrm{SCR}_{6}\right)$ : Only after proper training maintenance staff can make full use of the related tools and techniques, and reach the maintenance goals.

c) Aspect III (Value Added): The added value can be induced by implementing good maintenance program. These benefits include low inventories of spare parts, small production loss as the savings from increased availability of equipment and machine accounts to $54 \%$ of total savings Al-Najjar [2], and quick fault detection.

$\triangleright$ Spare Parts Inventories $\left(\mathrm{SCR}_{7}\right)$ : Comparatively more spare parts are required for corrective maintenance than other strategies. Spare parts for some machines are really expensive. Ineffective maintenance program leads to more failures, more spare parts and correspondingly more inventories to take care of them.

$\triangleright$ Production Loss $\left(\mathrm{SCR}_{8}\right)$ : The failure of more important machines in the production line often leads to higher production loss.

$\triangleright$ Fault Identification $\left(\mathrm{SCR}_{9}\right)$ : Fault diagnostic and prognostic techniques involved in the condition-based and predictive maintenance strategies aim at quick identifying and locating a fault for assisting maintenance engineer. As a result, the maintenance time can be reduced, and the availability of the production system may be improved.

d) Aspect IV (Execution Capability): The feasibility of maintenance strategies is divided into acceptance by labour and technique reliability.

$\triangleright$ Human Resource $\left(\mathrm{SCR}_{10}\right)$ : Managers and maintenance staff prefer the maintenance strategies that are easy to implement and understand. 
$>$ Technology $\left(\mathrm{SCR}_{11}\right)$ : Still under development, condition-based maintenance and predictive maintenance may be inapplicable for some complicated production facilities.

\section{Maintenance alternatives}

According to Zadeh [39] and Wang et al. [36], maintenance can be broadly classified as planned (proactive) maintenance and unplanned (reactive) maintenance. By proactive maintenance it is meant that maintenance activities are carried out prior to failure of equipment. The time based, age based, reliability centred and condition based maintenance strategies are form of planned or proactive maintenance, whereas corrective maintenance is a form of unplanned or reactive maintenance. Out of these different strategies, five have been evaluated in this study and these are:

$>$ Corrective Maintenance (CM): This alternative maintenance strategy is also named as fire-fighting maintenance, failure based maintenance or breakdown maintenance. When the corrective maintenance strategy is applied, maintenance is not implemented until failure occurs [32]. Corrective maintenance is the original maintenance strategy that occurred in industries long ago. It is considered as a feasible strategy in cases where profit margins are large [28, 34]. However, such a fire fighting mode of maintenance often causes serious damage to related facilities, personnel and environment respectively. Furthermore, increasing global competition and small profit margins have forced maintenance managers to apply more effective and reliable maintenance strategies [36]. $>$ Preventive Maintenance (PM): This type of maintenance strategy is based on equipment reliability characteristics. Maintenance is planned and performed periodically to reduce frequent and sudden failure. This maintenance strategy is also known as time-based preventive maintenance, where the term "time" may refer to calendar time, operating time or age. For performing time-based preventive maintenance, a decision support system is needed, and it is often difficult to define the most effective maintenance intervals due to lack of sufficient historical data in many cases $[17,36]$. This often leads to unnecessary maintenance, even deterioration of machines if incorrect maintenance is implemented [18].

$>$ Condition-Based Maintenance (CBM): Necessity for the application of condition-based maintenance is the availability of a set of measurements and data possession system to monitor real time equipment performance. Maintenance decision is made depending on the measured data from a set of sensor system when using the condition-based maintenance strategy. The monitored data of equipment parameters could tell engineers whether the situation is normal, allowing the maintenance staff to implement necessary maintenance before failure occurs. This maintenance strategy is often designed for rotating and reciprocating machines, e.g. turbines, centrifugal pumps and compressors. But limitations and deficiency in data coverage and quality reduce the effectiveness and accuracy of the condition-based maintenance strategy [3, 36]. $>$ Predictive Maintenance (PDM): In Predictive maintenance the acquired controlled parameter data is analysed and information is passed on to the maintenance staff when controlled value reaches the threshold value. Predictive maintenance is used to represent the maintenance strategy that enables to forecast the temporary trend of performance degradation and predict faults of machines by analysing the monitored parameters data. Fault prognostic is a recent technique employed by maintenance 
management [5, 8]. Wang [35] presented a survey of maintenance policies for deteriorating systems that aim at determining the optimal preventive maintenance (PM) period that optimises maintenance performance measures like maintenance cost rate, discounted cost rate, availability, mean time between failure, failure frequency etc. $>$ Opportunistic Maintenance (OM): The possibility of using opportunistic maintenance is determined by the nearness or concurrence of control or substitution times for different components on the same machine or plant. It is a maintenance strategy for a group of components in process line or plant not for the individual component. Opportunistic maintenance is a preventive maintenance that depends upon occurrence of equipment failure to take advantage of corrective maintenance opportunities. This type of opportunistic maintenance can lead to whole plant being shut at set times to perform all relevant maintenance interventions at the same time. Therefore, this maintenance strategy requires coordination and support from production personnel.

\section{Research methods}

The different tools used in present study have been discussed in this section.

\section{Fuzzy AHP}

The AHP was developed first by Saaty [25]. It is one of the simplest and popular tools for MCDM problems. To overcome limitations of subjective judgement of decision maker, uncertainty and imprecision, Saaty integrated AHP with fuzzy set theory. In present study qualitative information taken from experts in form of linguistic terms is converted into quantitative form using triangular membership function (TMF). The various steps involved in fuzzy AHP are as follows.

Step 1 Organizing problem hierarchically: The problem is structured as a family tree in this step. At the highest level is the overall goal of this decision making problem, and the alternatives are at the lowest level. Between them are criteria and sub criteria.

Step 2 Development of judgment matrices by pair wise comparisons: The criteria, sub-criteria and alternatives are compared pair-wise and defined from reciprocal comparison of different levels. For eliminating uncertainty and imprecision in judgement and to introduce fuzziness, well defined TMF are used. TFN have been used for representing fuzzy relative importance. The membership function of TFN is defined as follows.

$$
\mu \widetilde{A}(x)=\left\{\begin{array}{cc}
\frac{x-a}{b-a} & a \leq x \leq b \\
\frac{x-c}{b-c} & b \leq x \leq c \\
0 & \text { otherwise }
\end{array}\right\}
$$

where a,b,c are the upper, mean and lower bound respectively and $\tilde{A}$ is TFN represented by (a, b, c). After pair wise comparison, fuzzy judgement matrix $\tilde{A}$ is represented by Eq. 2 as follows. 


$$
\tilde{A}=\left\{\check{a}_{i j}\right\}=\left[\begin{array}{ccc}
\check{a}_{11} & \check{a}_{12} & \ldots \check{a}_{1 n} \\
\vdots & \vdots & \vdots \\
\check{a}_{n 1} & \check{a}_{n 2} & \ldots . . \check{a}_{n n}
\end{array}\right]
$$

Where $\mathrm{n}$ is the number of relative elements.

Step 3 Calculating local priorities from judgment matrices: Several methods for deriving local priorities (i.e. the local weights of criteria and the local scores of alternatives) from judgment matrices have been developed, such as Chang fuzzy extent analysis method, the eigenvector method, the logarithmic least squares method, the weighted least squares method and the goal programming method. In this study extent analysis of fuzzy AHP is used, as it gives accurate result.

Step 4 Alternatives ranking: The final step is to obtain global priorities (including global weights and global scores) by aggregating all local priorities with the application of a simple weighted sum. The final ranking of the alternatives are determined on the basis of these global priorities.

\section{Fuzzy synthetic extent analysis method}

This section presents fuzzy synthetic extent analysis method $[9,11]$ for calculating weights of criteria and sub-criteria. The steps involved are as follows.

Step 1: Fuzzy Synthetic Calculation: Let $X=\left\{x_{1}, x_{2} \ldots x_{n}\right\}$ be an object set, and $\mathrm{U}=\left\{\mathrm{u}_{1}, \mathrm{u}_{2}, \ldots . ., \mathrm{u}_{\mathrm{m}}\right\}$ be a goal set. According to the method of Zuo [40]; when each object is taken, then extent analysis for each goal is to be performed respectively. Then $\mathrm{M}^{1} \mathrm{~g}_{\mathrm{i}}, \mathrm{M}^{2} \mathrm{~g}_{\mathrm{i}} \ldots \mathrm{M}^{\mathrm{m}} \mathrm{g}_{\mathrm{i}} ; i=1,2 \ldots, \mathrm{n}$ becomes the values of extent analysis of $\mathrm{i}^{\text {th }}$ object for $\mathrm{m}$ goals. Where, all $\mathrm{M}^{\mathrm{j}} \mathrm{g}_{\mathrm{i}}$ are triangular fuzzy numbers. $\mathrm{j}(1,2, \ldots, \mathrm{m})$ represents the number of goals (criteria) considered for decision making and $\mathrm{i}(1,2, \ldots, \mathrm{n})$ represents the number of objects (alternatives) for which decision needs to be made. The value of fuzzy synthetic extent with respect to the $\mathrm{i}^{\text {th }}$ object is defined as follows.

$$
S_{i}=\sum_{j=1}^{m} M^{i} g_{i} \otimes\left[\sum_{i=1}^{n} \sum_{j=1}^{m} M^{i} g_{i}\right]^{-1}
$$

Step 2: Comparison of fuzzy values: To obtain the estimates for the vectors of weights under each criterion, we need to consider a principle of comparison for fuzzy numbers. It is required to determine the greatest or the least fuzzy number among the several fuzzy synthetic extents. Let $\mathrm{M}_{1}$ and $\mathrm{M}_{2}$ are convex fuzzy numbers and characterized by $\left(a_{1}, b_{1}, c_{1}\right)$ and $\left(a_{2}, b_{2}, c_{2}\right)$ respectively. The degree of possibility $(V)$ of $M_{1} \geq M_{2}$ is defined as follows.

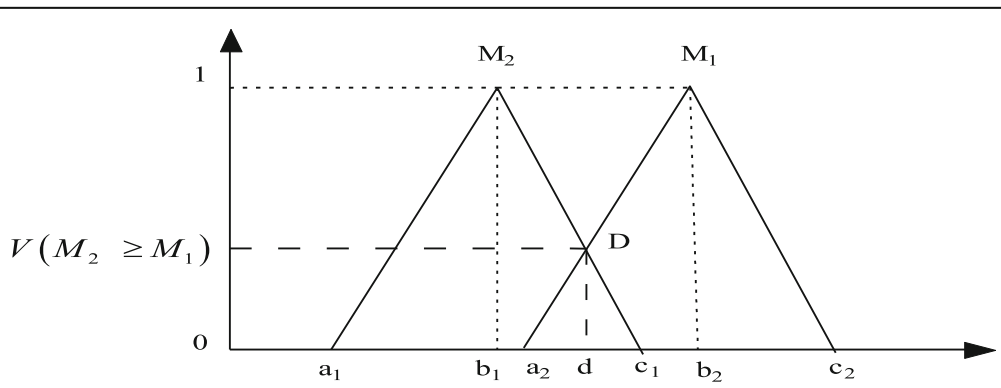

Fig. 3 Intersections between $\mathrm{M} 1$ and $\mathrm{M} 2$ 


$$
V\left(M_{1} \geq M_{2}\right)=\operatorname{Sup}_{x \geq y}\left[\min \mu_{M 1}(x), \mu_{M 2}(y)\right]
$$

Where sup represents suprenum (i.e. the least upper bound of a set)

If $b_{1} \geq b 2$ and $\mu_{M 1}(x)=\mu_{M 2}(y)$ then we have $V\left(M_{1} \geq M_{2}\right)=1$

To compare $M_{1}$ and $M_{2}$, we need both the values of $V\left(M_{1} \geq M_{2}\right)$ and $V\left(M_{2} \geq M_{1}\right)$. It is shown in Fig. 3 and represented by point D. Mathematically it is given by

$$
V\left(M_{2} \geq M_{1}\right)=\operatorname{hgt}\left(M_{1} \cap M_{2}\right)=\mu_{M 2}(d)
$$

Where $\mathrm{d}$ is the ordinate of the highest intersection point $\mathrm{D}$ between $\mu_{\mathrm{M} 1}$ and $\mu_{\mathrm{M} 2}$, and hgt is height of fuzzy set. The ordinate of $\mathrm{D}$ is given by the following equation

$$
V\left(M_{2} \geq M_{1}\right)=\operatorname{hgt}\left(M_{1} \cap M_{2}\right)=\mu_{M 2}(d)=\left(a_{2}-c_{1}\right) /\left[\left(b_{1}-c_{1}\right)-\left(b_{2}-a_{2}\right)\right]
$$

Step 3: Computing priority weights and normalized weight vector: The degree of possibility for k convex fuzzy number $M_{i} \sim M_{i+1} \geq K,(i=1,2,3, \ldots \ldots ., K)$ is defined [11] as follow.

$$
\begin{aligned}
& V\left(M \geq M_{1}, M 2 \ldots \ldots M_{k}\right)=V\left[\left(M \geq M_{1}\right) \text { and }\left(M \geq M_{2}\right) \text { and } \ldots . \text { and }\left(M \geq M_{k}\right)\right] \\
& =\min \mathrm{v}\left(\mathrm{M} \geq \mathrm{M}_{\mathrm{i}}\right) ; \mathrm{i}=1,2, \ldots, \mathrm{k} \\
& =d\left(A_{i}\right)=\min V\left(S_{i} \geq S_{K}\right)
\end{aligned}
$$

Then, for $K=1,2, \ldots, \mathrm{n} ; K \neq i$

The weight vector is given by:

$$
W^{\prime}=\left(\dot{d}^{\prime}\left(A_{1}\right), \dot{d}^{\prime}\left(A_{2}\right), \ldots, \dot{d}^{\prime}\left(A_{n}\right)\right)^{\mathrm{T}}
$$

The normalized weight vector is obtained by normalization

$$
W=\left(d\left(A_{1}\right), d\left(A_{2}\right), \ldots \ldots, d\left(A_{n}\right)\right)^{\mathrm{T}}
$$

\section{Fuzzy TOPSIS}

TOPSIS method, a MADM approach was proposed and developed by Hwang and Yoon [13]. Due to inherent impreciseness and vagueness of expert judgement, fuzzy TOPSIS methodology was developed. Steps involved in computations by using fuzzy TOPSIS are as follow.

Step 1: Let there are $m$ possible alternatives $A=\left(A_{1}, A_{2}, \ldots \ldots \ldots . . ., A_{m}\right)$ which are to be evaluated w.r.t n criteria, $C=\left(C_{1}, C_{2}, \ldots \ldots . . C_{n}\right)$ with weights of criteria $w_{j}(j=1,2 \ldots . ., n)$. Also if $\mathrm{k}$ are the decision makers, then performance rating of each expert $D_{k}(1, k)$ for each alternative $A_{i}(1, \quad m)$ w.r.t criteria $C_{j} \quad(1, \quad m)$ are denoted by $\breve{R}_{k}=\tilde{x}_{i j k}(i=1,2 \ldots m ; j=1,2 \ldots, n ; k=1,2 \ldots ., k)$ with membership function $\mu_{\breve{R k}}(x)$. The scale used for rating of alternatives is as follows. [36]

Step2: The next step is computation of aggregate fuzzy rating, denoted by $\tilde{x}_{i j}$. If the fuzzy rating for all decision makers is described by TFN such that

$$
\tilde{R}_{k}=\left(a_{k}, b_{k},, c_{k}\right), \quad k=1,2, \ldots \ldots k
$$

The aggregated fuzzy rating is given by 


$$
\tilde{R}=(a, b, c), \quad k=1,2, \ldots \ldots k
$$

Where $a=\min \left\{a_{k}\right\} ; \quad b=1 / k \sum_{k=1}^{k} b_{k} ; \quad c=\max \left\{c_{k}\right\}$

If there are $\mathrm{k}$ decision makers then fuzzy rating is represented as:

$$
\tilde{x}_{i j k}=\left(a_{i j k},, b_{i j k},, c_{i j k}\right), \quad i=1,2,3 \ldots \ldots \ldots \ldots \ldots \mathrm{m} ; j=1,2,3 \ldots \ldots \ldots \ldots \ldots \ldots \mathrm{n}
$$

And the aggregated fuzzy rating $\left(\tilde{x}_{i j}\right)$ of alternatives w.r.t each criteria is given by

$$
\tilde{x}_{i j k}=\left(a_{i j}, b_{i j}, c_{i j}\right)
$$

Where $a_{i j}=\min \left\{a_{i j k}\right\} ; \quad b_{i j}=1 / k \sum_{k=1}^{k} b_{i j k} ; \quad c_{i j}=\max \left\{c_{i j k}\right\}$

Step3: Using Table 1 fuzzy decision matrix (FDM) for alternatives $(\tilde{D})$ as follows.

$$
A_{2}\left(\begin{array}{cccc}
C_{1} & C_{2} & \ldots \ldots & C_{N} \\
\check{x}_{11} & \check{x}_{11} & \ldots \ldots & \check{x}_{1 N} \\
\check{x}_{21} & \check{x}_{22} & \ldots \ldots & \check{x}_{2 N} \\
\ldots \ldots \ldots & . & & \\
\check{x}_{M 1} & \check{x}_{M 2} & \ldots \ldots & \check{x}_{M N}
\end{array}\right]
$$

Where $i=1,2,3$. . $\mathrm{M} ; \mathrm{j}=1,2,3$....... ... N and $x_{i j}$ is the rating of alternative $A_{i}$ with respect to criterion $C_{j}$ evaluated by $k$ number of experts.

Step4: Next step is to normalize fuzzy decision matrix (NFDM).

$$
\tilde{R}=\left[\tilde{r}_{i j}\right]_{m x n}
$$

Where $i=1,2,3$. $m ; j=1,2,3$.

\begin{tabular}{|c|c|}
\hline Uncertain Judgement & Fuzzy Score \\
\hline About equal & $(1 / 2,1,2)$ \\
\hline About $X$ time more important ${ }^{a}$ & $(X-1, X, X+1)$ \\
\hline About $X$ time less important & $(1 /(X+1), 1 / X, 1 /(X-1)$ \\
\hline Between $Y$ and $Z$ times more important ${ }^{\beta}$ & $(Y,(Y+Z) / 2, Z)$ \\
\hline Between $Y$ and $Z$ times less important & $(1 / Z, 2 / Y+Z, 1 / Y)$ \\
\hline
\end{tabular}

Normalization process can be done by using following formula:

$$
\begin{aligned}
\tilde{r}_{i j} & =\left(\frac{a_{i j}}{c^{*}{ }_{j}}, \frac{b_{i j}}{c^{*}{ }_{j}}, \frac{c_{i j}}{c^{*}{ }_{j}}\right) \text { and } \tilde{V}_{1}^{*}=\left(\tilde{c}_{j}^{*}, \tilde{c}_{j}^{*}, \tilde{c}_{j}^{*}\right) \text { and } \tilde{c}_{j}^{*} \\
& =\underbrace{\max }_{i}\left\{\tilde{c}_{i j}\right\} \\
\tilde{r}_{i j} & =\left(\frac{a_{j}^{-}}{c_{i j}}, \frac{a_{j}^{-}}{b_{i j}}, \frac{a_{j}^{-}}{a_{i j}}\right) \text { and } a_{j}^{-}=\min a_{i j} \tilde{a}_{j}^{-}=\underbrace{\min }_{i}\left\{\tilde{a}_{i j}\right\}
\end{aligned}
$$

Table 1 Fuzzy judgement scale for matrix generation

${ }^{a} X=2,3, \ldots 9$

${ }^{\beta} Y, Z=1,2,3 \ldots . ., 9, Y<Z$ 
Step5: Next step is to form a weighted normalized decision matrix (WFNDM). Here normalized fuzzy decision matrix is multiplied with weights of the evaluation attributes. These weights have been calculated using fuzzy extent analysis method (section "Fuzzy synthetic extent analysis method").

$$
\begin{aligned}
& \tilde{v}=\left[\tilde{v}_{i j}\right]_{m x n} \\
& \tilde{v}_{i j}=\tilde{r}_{i j} \otimes \tilde{w}_{i j}
\end{aligned}
$$

This fuzzy weighted normalized decision matrix is an all-inclusive matrix, which takes care of attributes value and their relative importance. The weighted normalized fuzzy decision matrix is used to determines fuzzy ideal solution (FIS) and fuzzy anti ideal solution (FAIS) respectively. Two methods can be used for calculation of FIS and FAIS that are as follows.

$$
\begin{aligned}
A^{+} & =\left(\tilde{V}_{1}^{*}, \tilde{V}_{2}^{*}, \tilde{V}_{3}^{*}, \ldots \ldots . . \tilde{V}_{n}^{*}\right) \text { where } \tilde{V}_{1}^{*}=\left(\tilde{c}_{j}^{*}, \tilde{c}_{j}^{*}, \tilde{c}_{j}^{*}\right) \text { and } \tilde{c}_{j}^{*} \\
& =\underbrace{\max }_{i}\left\{\tilde{c}_{i j}\right\} \\
A^{-} & =\left(\tilde{V}_{1}^{-}, \tilde{V}_{2}^{-}, \tilde{V}_{3}^{-}, \ldots \ldots . . \tilde{V}_{n}^{-}\right) \text {where } \tilde{V}_{1}^{-}=\left(\tilde{a}_{j}^{*}, \tilde{a}_{j}^{*}, \tilde{a}_{j}^{*}\right) \text { and } \tilde{a}_{j}^{-} \\
& =\underbrace{\min }_{i}\left\{\tilde{a}_{i j}\right\}
\end{aligned}
$$

The Euclidian distance $\left(D_{i}^{+}\right.$and $\left.\mathrm{D}_{i}^{-}\right)$of each alternative from $\mathrm{A}^{+}$and $\mathrm{A}^{-}$can be calculated as

$$
D_{i}^{+}=\sum_{j=1}^{n} D\left(\tilde{v}_{i j}, \tilde{V}_{J}^{+}\right)
$$

Where $i=1,2,3 \ldots \ldots \ldots \ldots . . . m ; j=1,2,3 \ldots \ldots \ldots \ldots \ldots . . . n$

$$
D_{i}^{-}=\sum_{j=1}^{n} D\left(\tilde{v}_{i j}, \tilde{V}_{J}^{-}\right)
$$

Where $\mathrm{i}=1,2,3 \ldots \ldots \ldots \ldots . . \mathrm{m} ; \mathrm{j}=1,2,3 \ldots \ldots \ldots \ldots \ldots . . . \mathrm{n}$

Where $d_{v}(\tilde{a}, \tilde{b})$ is the distance measurement between two fuzzy number $\tilde{a}$ and $\tilde{b}$ is given by

$$
d_{v}(\tilde{a}, \tilde{b})=\sqrt{\left(\frac{1}{3}\right)\left[\left(a_{1}-b_{1}\right)^{2}+\left(a_{2}-b_{2}\right)^{2}+\left(a_{3}-b_{3}\right)^{2}\right]}
$$

The next step is to calculate closeness coefficient. This step solves the similarities to an ideal solution by formula:

$$
C C_{i=} D_{i}^{-} /\left(D_{i}^{+}+D_{i}^{-}\right)
$$

Where $\mathrm{i}=1,2,3 \ldots \ldots \ldots \ldots . . . . \mathrm{m}$

Ranking of alternatives is done in accordance with decreasing value of indices $C C_{i}$, indicating most and least preferred feasible optimal solution.

\section{Graphical methods}

In preceding section, mathematical relations were used to rank alternative. This section explores graphical method to process and evaluate present data. In this method data in matrix is processed and is represented in form of line and spider graph respectively. 
This method is useful for representing alternative solution using weighted normalized decision matrix database and benchmark solution. The area under the curve can be used for evaluation and comparison of different alternatives.

Line graphs In this approach magnitude of attribute is plotted on Y-axis and attributes on $\mathrm{X}$-axis. For attributes whose minimum values are preferred, reciprocal of magnitude is used for plotting. The line graphs can be plotted for fuzzy decision matrix, normalized fuzzy decision matrix and weighted normalized fuzzy decision matrix. For this all values of $d_{i j}, v_{i j}, r_{i j}$ have to be changed into crisp values.

The area under the curve can be found out as follows.

Let the width between two attributes on $\mathrm{X}$-axis as unity and $d_{i j}, r_{i j}$, $v_{i j}$ are the elements of FDM, NFDM and WNFDM respectively.

Area under line graph of attributes for FDM can be found out

$$
A D_{i}^{L}=\left(d_{i, 1}+2\left(d_{i, 2}+d_{i, 3}+\ldots \ldots \ldots \ldots \ldots+d_{i, n-1}\right) / 2\right.
$$

Similarly area under graph for $A N_{i}^{L}$ and $A V_{i}^{L}$ can be found out.

Where $A D_{i}^{L}$ is area under the line for FDM $A N_{i}^{L}$ is area under line graph for NFDM and $A V_{i}^{L}$ is area under line graph for WNFDM.

Spider diagram In this method attributes are considered to form a spider graph. The angle $\theta$ (theta) between attributes axes can be calculated as $\theta=2 \pi / n$, where $n$ is the number of attributes under consideration. Area enclosed by the polygon is calculated as follows.

Let $d_{i j}$ represents value of $\mathrm{j}^{\text {th }}$ attribute in the $\mathrm{i}^{\text {th }}$ alternative along $\theta_{\mathrm{i}}$.

Let $r_{i j}$ represents normalized value of $\mathrm{j}^{\text {th }}$ attributes in the $\mathrm{i}^{\text {th }}$ alternative along $\theta_{\mathrm{i}}$.

Let $v_{i j}$ represents weighted normalized value of $\mathrm{j}^{\text {th }}$ attribute in the $\mathrm{i}^{\text {th }}$ alternative along $\theta_{\mathrm{i}}$.

$$
A D_{i}^{S}=\left(\frac{\sin \theta}{2}\right) \sum_{j=1}^{n} d_{i j} d_{i, j+1} ; \text { where } \quad d_{i, j+1}=d_{i, 1}
$$

Similarly $A N_{i}^{S}, A V_{i}^{S}$ can also be calculated.

Where $A D_{i}^{S}$ is area under the spider graph for FDM, $A N_{i}^{S}$ is area under the spider graph for NFDM, $A V_{i}^{S}$ is area under the spider graph for WNFDM respectively.

Ranking and selection by using coefficient of similarity (COS) Once all $A D_{i}^{S}, A N_{i}^{S}$ and $A V_{i}^{S}$ have been calculated, these values will be compared with benchmarks.

Let the coefficient of similarity is the ratio of area under the curve or enclosed by the polygon for the alternatives. Coefficient of similarity (COS) on the basis of WNFDM as follows.

$$
\begin{aligned}
& C O S_{j}^{F D M}=A D_{j} / A D_{I} \\
& C O S_{j}^{N F D M}=A N_{j} / A N_{I} \\
& C O S_{j}^{W N F D M}=A V_{j} / A V_{I}
\end{aligned}
$$

Where $A D_{j}, A N_{j}, A V_{j}$ are calculated from Eq. 25 for line graph and Eq. 26 for spider graph respectively. The values $A D_{I}, A N_{I}, A V_{I}$ are calculated from Eq. 25 for line graph and Eq. 26 for spider graph respectively for benchmarks. 


\section{Case description}

To delineate application of methodology discussed, a case from Panipat Thermal Power Station (PTPS) in Haryana, situated in northern India, has been selected. This plant has a total installed generation capacity of $1360 \mathrm{MW}$. The plant has 8 units: 4 units of $110 \mathrm{MW}$ each, 2 units of $210 \mathrm{MW}$ each and 2 units of $250 \mathrm{MW}$ each. To ensure uninterrupted supply of electricity to its end users, critical importance is given to maintenance work of equipment like pumps, fans, boilers, condenser tubes, turbine blades etc. by the management. The plant under study is Unit 8 with capacity of producing $250 \mathrm{MW}$. The steam generating system consists of FD fan, condenser tank, DM tank, motors, boiler, economiser, ID fan respectively. The flow diagram is shown in Fig. 4. The boiler under study is a vertical water tube boiler, BHEL make, with MTTF of 3-4 months and MTTR of 25-36 h. Presently, CM strategy is used in considered unit. The plant engineer is not satisfied with the current maintenance methods and wants to improve maintenance program for improving availability of plant and reducing maintenance budget.

By personal interactions with management of thermal power plant criteria, sub criteria and alternative are taken into account. Hierarchy structure is constructed correspondingly, as shown in Fig. 5. The fuzzy comparison judgment matrices are formulated according to the suggestions of the maintenance staff, which is included in Additional file 1: Annexure A.

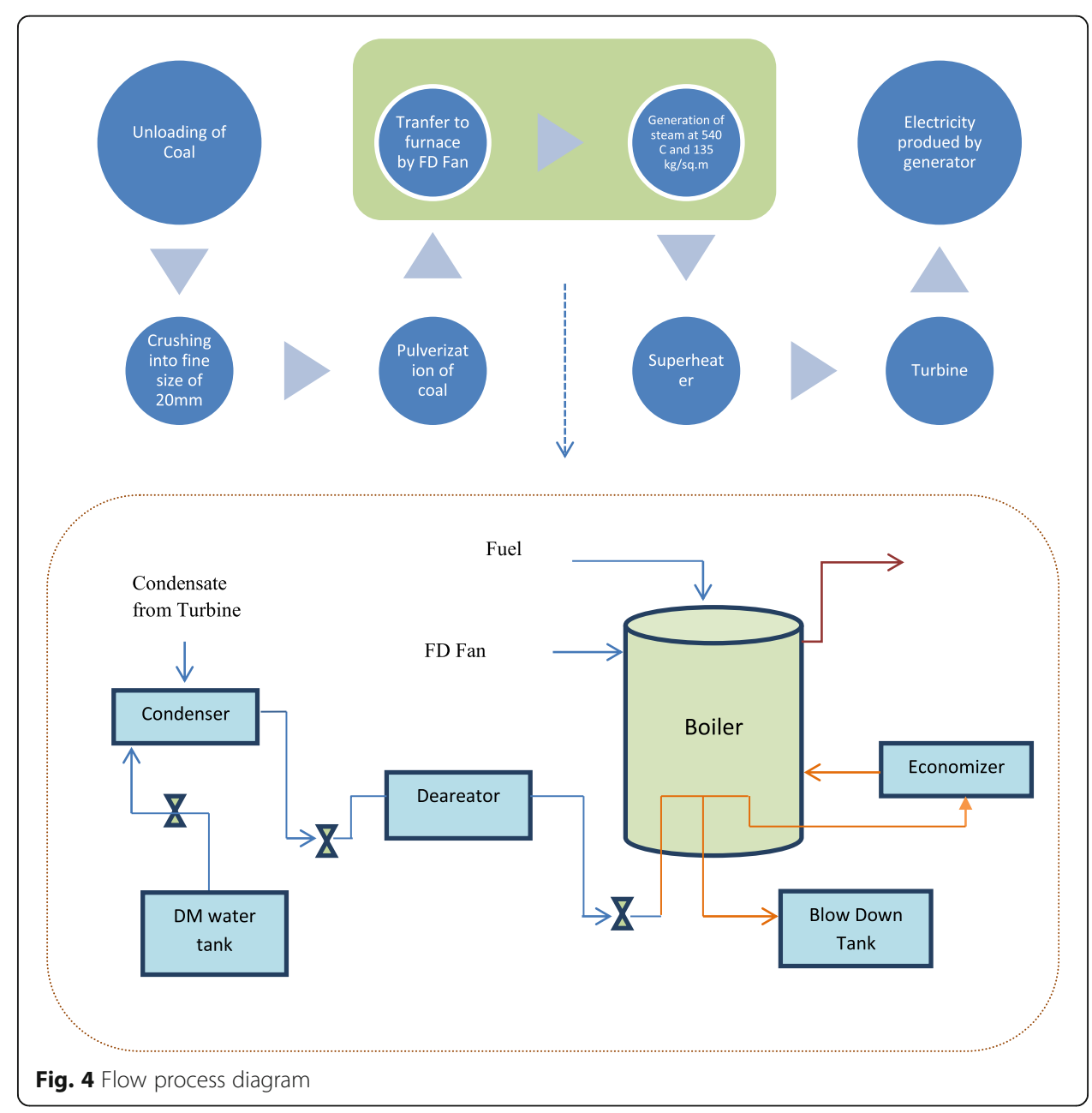




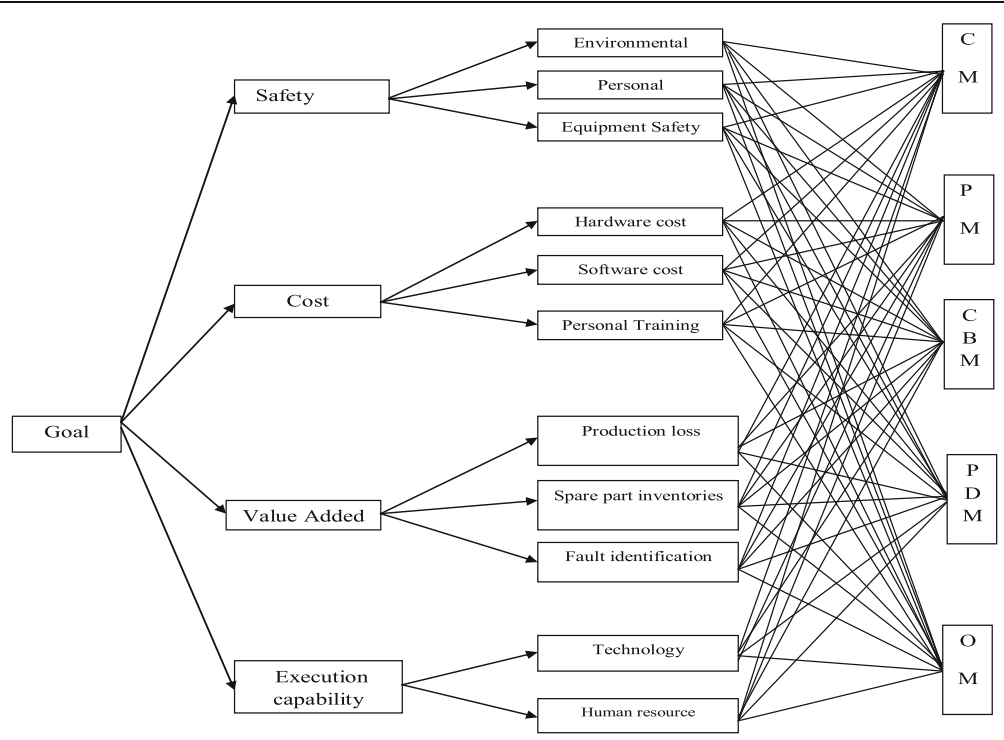

Fig. 5 Hierarchy structure

\section{Discussion and Result}

Using equations from 3 to 11 and Table 1, local weights of criteria and sub-criteria have been found out. It has been shown in Table 2 . Here $\mathrm{W}_{1}, \mathrm{~W}_{2} \ldots \ldots . \mathrm{W}_{4}$ are local weights of criteria and $\mathrm{W}_{11}$ $\mathrm{W}_{42}$ are local weights of sub criteria.

Where $\mathrm{W}_{\mathrm{i}}$ is weight of criteria, for $i=1,2,3, \ldots \ldots \ldots \ldots, \mathrm{m} ; \mathrm{W}_{\mathrm{ij}}$ is weight of sub-criteria, for $\mathrm{j}=1,2,3, \ldots . . \mathrm{n}$ for each $\mathrm{i}$.

The global weight is calculated by multiplying local weight of the criteria and sub criteria. This global weight is used to calculate the global score for the alternatives. Table 3 shows the result of extent analysis of fuzzy AHP. The global score determine the optimum maintenance strategy. The global score for C.M alternative is calculated as:

$$
\begin{aligned}
& 0.011 \times 0.1063+0.014 \times 0.2857+\ldots \ldots \ldots . .+0.054 \times .0262+0.332 \times 0.0784 \\
& \quad=\mathbf{0 . 1 6 9 3 5 1 3}
\end{aligned}
$$

Table 2 Weights of criteria and sub-criteria

\begin{tabular}{llll}
\hline $\begin{array}{l}\text { Criteria Weights } \\
\left(\mathrm{W}_{\mathrm{i}}\right)\end{array}$ & Sub-criteria $\left(\mathrm{SCR}_{\mathrm{j}}\right)$ & Sub-criteria Weights $\left(\mathrm{W}_{\mathrm{ij}}\right)$ & $\begin{array}{l}\text { Global Weights } \\
\left(\mathrm{W}_{\mathrm{i}}{ }^{*} \mathrm{~W}_{\mathrm{ij}}\right)\end{array}$ \\
\hline 0.5318 & Environment $\mathrm{SCR}_{1}$ & 0.1999 & 0.1063 \\
$($ Safety) & Personnel SCR & 0.5373 & 0.2857 \\
& Equipment Safety SCR & 0.2627 & 0.1397 \\
0.1654 & Hardware cost SCR & 0.6634 & 0.1097 \\
$($ Cost) & Software cost SCR & 0.0096 & 0.0016 \\
& Personnel training SCR & 0.327 & 0.0538 \\
0.1976 & Production loss SCR & 0.4363 & 0.0862 \\
Value Added) & Spare part inventories SCR & 0.3035 & 0.06 \\
& Fault identification $S C R_{9}$ & 0.2602 & 0.0514 \\
0.1052 (Execution Capability) & Technology SCR & 0.255 & 0.0262 \\
& Human resource $\mathrm{SCR}_{11}$ & 0.745 & 0.0784 \\
\hline
\end{tabular}


Table 3 Global scores of alternatives

\begin{tabular}{lllllll}
\hline Sub Criteria/Goal & C.M & P.M & C.B.M & O.M & P.D.M & Global wt \\
\hline Environment SCR & 0.011 & 0.142 & 0.125 & 0.254 & 0.468 & 0.1063 \\
Personnel SCR & 0.014 & 0.187 & 0.262 & 0.051 & 0.487 & 0.2857 \\
Equipment Safety SCR & 0.019 & 0.103 & 0.141 & 0.278 & 0.459 & 0.1397 \\
Hardware cost SCR & 0.405 & 0.434 & 0.006 & 0.151 & 0.004 & 0.1097 \\
Software cost SCR & 0.53 & 0.209 & 0.175 & 0.04 & 0.045 & 0.0016 \\
Personnel training SCR & 0.601 & 0.205 & 0.013 & 0.167 & 0.014 & 0.0538 \\
Production loss SCR & 0.323 & 0.055 & 0.072 & 0.227 & 0.323 & 0.0862 \\
Spare part inventories SCR & 0.211 & 0.005 & 0.318 & 0.007 & 0.459 & 0.06 \\
Fault identification SCR & 0.063 & 0.197 & 0.155 & 0.049 & 0.535 & 0.0514 \\
Technology SCR & 0.54 & 0.268 & 0.044 & 0.026 & 0.121 & 0.0262 \\
Human resource SCR & 0.332 & 0.286 & 0.13 & 0.19 & 0.063 & 0.0784 \\
Global score & 0.1693513 & 0.1864936 & 0.1540744 & 0.144104 & $\mathbf{0 . 3 4 5 2 6 1 6}$ & \\
\hline
\end{tabular}

Similarly, scores of other maintenance policy is calculated, which is shown in Table 6. The maximum value of the global score gives the optimum maintenance strategy for FAHP. The results are shown in Table 6.

Using equations from 12-15a fuzzy decision matrix (FDM) is prepared, which becomes basis for developing NFDM. Next step is the normalization of FDM. Normalization is required for removing inconsistency in data received, e.g. there can be data on different scales which needs to be adjusted on common scale. Using equation from 16 to 18 normalized fuzzy decision matrix (NFDM) is prepared.

Next weighted normalized fuzzy decision matrix $\left(\mathrm{V}_{\mathrm{ij}}\right)$ is obtained by multiplying respective weights with elements of normalized decision matrix. It is shown in Table 4.

To minimize maintenance budget all criteria must be cost effective. Therefore distance from fuzzy ideal solution (FIS) and fuzzy anti ideal solution (FIAS) can be computed by using equation from 19 to 23. Table 5 shows FIS and FAIS values for criteria from weighted normalized fuzzy decision matrix. The computed value of closeness coefficient is shown in Table 6.

Using Eq. 24 ranking of alternative as computed by fuzzy TOPSIS have been shown in Table 6.

The values for $A V_{j}, A V_{I}$ are calculated by Eqs. 25 and 26 for line graph and spider graph respectively. The coefficient of similarity and subsequently ranking of alternatives have been calculated by using Eq. 29. The corresponding results of ranking by line graph and spider graph have been shown in figure, and reported in Table 6 respectively.

The ranking by different methods have been shown from Figs. 5, 6, 7 and 8.

The results are as follow.

i. From Table 6 for fuzzy AHP, it is clear that PDM has highest score of 0.35 (corrected to two decimal places), whereas OM has lowest score of 0.14. The ranking according to FAHP is $\mathrm{PDM}>\mathrm{PM}>\mathrm{PM}>\mathrm{CBM}>\mathrm{OM}$. This ranking order is also shown by height of bar-graph in Fig. 6. 
Table 4 Weighted normalized fuzzy decision matrix

\begin{tabular}{llllll}
\hline & $\mathrm{C} . \mathrm{M}$. & P.M. & $\mathrm{C} . \mathrm{B} . \mathrm{M}$. & $0 . \mathrm{M}$. & P.D.M. \\
\hline $\mathrm{SCR}_{1}$ & $(0.00163,0.00475$, & $(0.003468,0.01204$, & $(0.00706,0.02424$, & $(0.00429,0.01711$, & $(0.02302,0.06892$, \\
& $0.01645)$ & $0.04663)$ & $0.09097)$ & $0.07039)$ & $0.22856)$ \\
$\mathrm{SCR}_{2}$ & $(0.00557,0.01743$, & $(0.02015,0.07755$, & $(0.02370,0.0909$, & $(0.02015,0.04444$, & $(0.03949,0.14813$, \\
& $0.05320)$ & $0.27227)$ & $0.38337)$ & $0.16117)$ & $0.49291)$ \\
$\mathrm{SCR}_{3}$ & $(0.00260,0.00982$, & $(0.00555,0.02488$, & $(0.01099,0.04715$, & $(0.01262,0.05894$, & $(0.021556,0.08922$, \\
& $0.03481)$ & $0.09863)$ & $0.17213)$ & $0.23208)$ & $0.31911)$ \\
$\mathrm{SCR}_{4}$ & $(0.00614,0.02408$, & $(0.00730,0.02568$, & $(0.00229,0.01033$, & $(0.00307,0.01348$, & $(0.00095,0.00326$, \\
& $0.09628)$ & $0.09628)$ & $0.04223)$ & $0.05878)$ & $0.01351)$ \\
$\mathrm{SCR}_{5}$ & $(0.00359,0.01167$, & $(0.00224,0.00695$, & $(0.00055,0.00209$, & $(0.00155,0.00556$, & $(0.00098,0.00324$, \\
& $0.04481)$ & $0.03369)$ & $0.00896)$ & $0.0209)$ & $0.01326)$ \\
$\mathrm{SCR}_{6}$ & $(0.00469,0.01945$, & $(0.00194,0.00944$, & $(0.00159,0.00655$, & $(0.00163,0.00756$, & $(0.00063,0.00231$, \\
& $0.06390)$ & $0.03369)$ & $0.02227)$ & $0.03195)$ & $0.00823)$ \\
$\mathrm{SCR}_{7}$ & $(0.00313,0.01065$, & $(0.01283,0.04314$, & $(0.01627,0.06036$, & $(0.02066,0.07634$, & $(0.02986,0.09853$, \\
& $0.02735)$ & $0.13090)$ & $0.16991)$ & $0.24209)$ & $0.29186)$ \\
$\mathrm{SCR}_{8}$ & $(0.00055,0.00180$, & $(0.00175,0.00709$, & $(0.00471,0.01768$, & $(0.00171,0.00699$, & $(0.00598,0.02269$, \\
& $0.00642)$ & $0.03094)$ & $0.06888)$ & $0.03012)$ & $0.08756)$ \\
$\mathrm{SCR}_{9}$ & $(0.00078,0.00296$, & $(0.00112,0.00556$, & $(0.00284,0.01276$, & $(0.00130,0.00683$, & $(0.00691,0.02594$, \\
& $0.02092)$ & $0.02628)$ & $0.05230)$ & $0.03556)$ & $0.09807)$ \\
$\mathrm{SCR}_{10}$ & $(0.00629,0.01749$, & $(0.00328,0.01014$, & $(0.00181,0.00547$, & $(0.00139,0.00453$, & $(0.00085,0.00217$, \\
& $0.06914)$ & $0.04285)$ & $0.02200)$ & $0.02304)$ & $0.00953)$ \\
$\mathrm{SCR}_{11}$ & $(0.00755,0.02617$, & $(0.00655,0.02141$, & $(0.00302,0.01038$, & $(0.00343,0.01268$, & $(0.00237,0.00737$, \\
& $0.09857)$ & $0.07886)$ & $0.04162)$ & $0.05476)$ & $0.03198)$ \\
\hline & & & & & \\
\hline
\end{tabular}

ii. From Table 6 for fuzzy TOPSIS, it is clear that PDM has highest score of 0.84 , whereas $\mathrm{CM}$ has lowest score of 0.16 . The ranking according to F TOPSIS is $\mathrm{PDM}>\mathrm{CBM}>\mathrm{OM}>\mathrm{PM}>\mathrm{CM}$. his ranking order is also shown by height of bar-graph in Fig. 7.

iii. From Table 6 and Figs. 8 and 9 respectively, observations reported are as follows.

a) For line graph, PDM has highest score of 0.86 , whereas CM has lowest score of 0.20 . The ranking is $\mathrm{PDM}>\mathrm{CBM}>\mathrm{OM}>\mathrm{PM}>\mathrm{CM}$.

b) For spider graph, PDM has highest score of 0.82, whereas CM has lowest score of 0.03. The ranking is $\mathrm{PDM}>\mathrm{CBM}>\mathrm{OM}>\mathrm{PM}>\mathrm{CM}$.

Table 5 Fuzzy ideal solution (FIS) and fuzzy anti-idle solution (FAIS)

\begin{tabular}{|c|c|c|}
\hline \multirow[t]{2}{*}{ Criteria } & Fuzzy ideal solution (FIS) & Fuzzy anti ideal solution (FAIS) \\
\hline & $\mathrm{A}^{+}$ & $A^{-}$ \\
\hline $\mathrm{SCR}_{1}$ & $(0.02302,0.06892,0.22856)$ & $(0.00163,0.00475,0.01645)$ \\
\hline $\mathrm{SCR}_{2}$ & $(0.03949,0.14813,0.49291)$ & $(0.00557,0.01743,0.05320)$ \\
\hline $\mathrm{SCR}_{3}$ & $(0.021556,0.08922,0.31911)$ & $(0.00260,0.00982,0.03481)$ \\
\hline $\mathrm{SCR}_{4}$ & $(0.00730,0.02568,0.09628)$ & $(0.00095,0.00326,0.01351)$ \\
\hline $\mathrm{SCR}_{5}$ & $(0.00359,0.01167,0.04481)$ & $(0.00055,0.00209,0.00896)$ \\
\hline $\mathrm{SCR}_{6}$ & $(0.00469,0.01945,0.06390)$ & $(0.00063,0.00231,0.00823)$ \\
\hline $\mathrm{SCR}_{7}$ & $(0.02986,0.09853,0.29186)$ & $(0.00313,0.01065,0.02735)$ \\
\hline $\mathrm{SCR}_{8}$ & $(0.00598,0.02269,0.08756)$ & $(0.00055,0.00180,0.00642)$ \\
\hline $\mathrm{SCR}_{9}$ & $(0.00691,0.02594,0.09807)$ & $(0.00078,0.00296,0.02092)$ \\
\hline $\mathrm{SCR}_{10}$ & $(0.00629,0.01749,0.06914)$ & $(0.00085,0.00217,0.00953)$ \\
\hline $\mathrm{SCR}_{11}$ & $(0.00755,0.02617,0.09857)$ & $(0.00237,0.00737,0.03198)$ \\
\hline
\end{tabular}


Table 6 Ranking of alternative by different methods

\begin{tabular}{lllllllll}
\hline & FAHP & Rank & F TOPSIS & Rank & Line graph & Rank & Spider graph & Rank \\
\hline C.M. & 0.169351 & 3 & 0.163288 & 5 & 0.195727 & 5 & 0.031128 & 5 \\
P.M. & 0.186494 & 2 & 0.362805 & 4 & 0.468107 & 4 & 0.161401 & 4 \\
C.B.M. & 0.154074 & 4 & 0.481716 & 2 & 0.563022 & 2 & 0.300368 & 2 \\
O.M. & 0.144104 & 5 & 0.410769 & 3 & 0.499558 & 3 & 0.192916 & 3 \\
P.D.M. & 0.345262 & 1 & 0.841241 & 1 & 0.864613 & 1 & 0.817683 & 1 \\
\hline
\end{tabular}

The Figs. 10 and 11 shows area under the line graph and spider graph respectively. It is quite obvious from figures that $\mathrm{PDM}$ has highest area under line and spider graph respectively. Also, it is clear from that $\mathrm{SCR}_{1}, \mathrm{SCR}_{2}, \mathrm{SCR}_{3}, \mathrm{SCR}_{7}, \mathrm{SCR}_{8}, \mathrm{SCR}_{9}$ are pertinent criteria for present study. The ranking of criteria from line graph and spider is as follows.

a) For line graph method: $\mathrm{SCR}_{2}>\mathrm{SCR}_{3}, \mathrm{SCR}_{7}>\mathrm{SCR}_{1}>\mathrm{SCR}_{8}>\mathrm{SCR}_{9}$.

b) For spider graph method: $\mathrm{SCR}_{2}>\mathrm{SCR}_{3}>\mathrm{SCR}_{1}>\mathrm{SCR}_{7}>\mathrm{SCR}_{8}>\mathrm{SCR}_{9}$.

\section{Conclusion}

Following results and conclusions can be drawn from present research. These are as following:

a) The closeness coefficient and COS values of all the alternatives have been listed in Table 6, for fuzzy AHP, fuzzy Topsis method, Line Graph method and Spider Diagram method respectively.

b) There appears good amount of synergy between Fuzzy Topsis method, Line Graph method of ranking and Spider Diagram method of ranking respectively, as from all

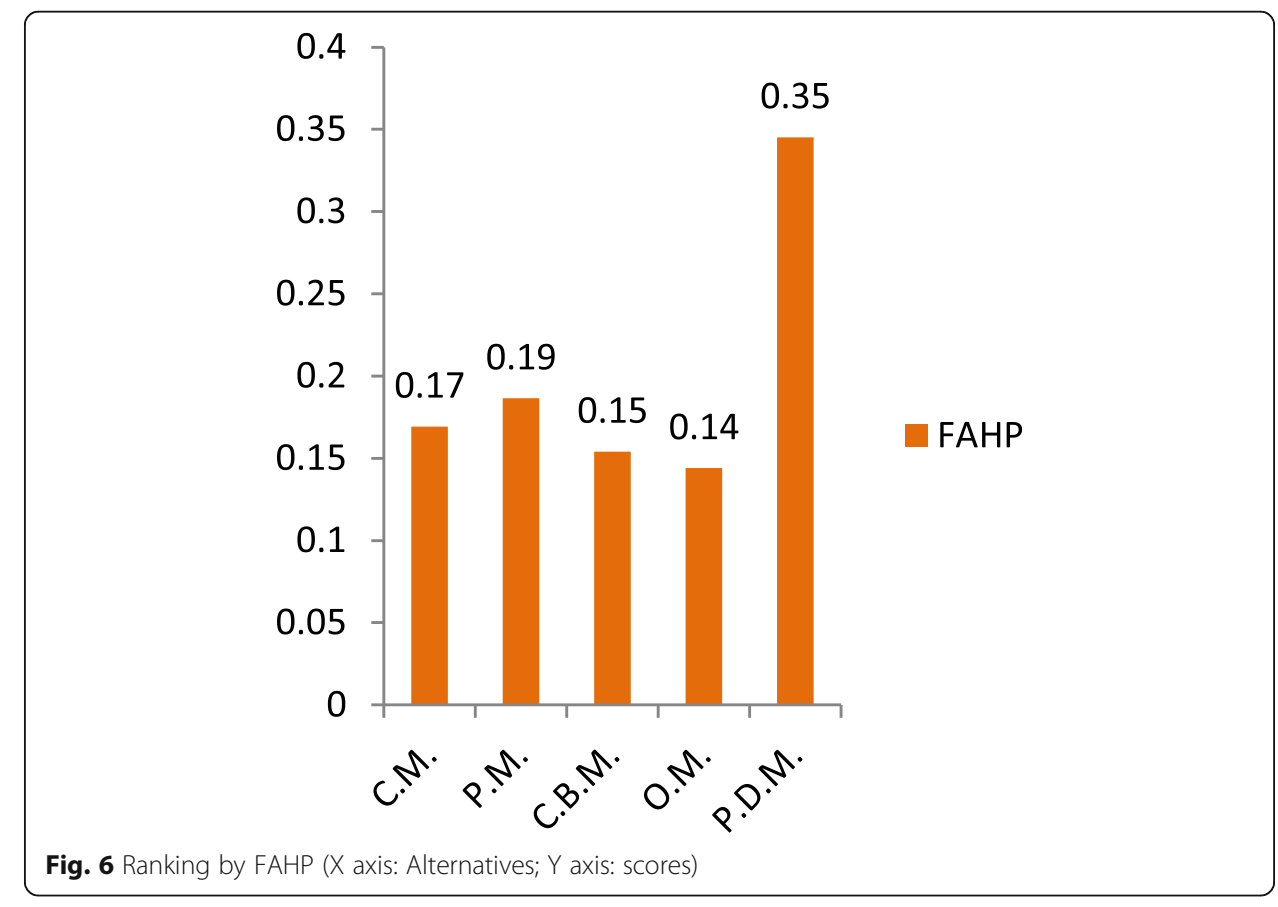




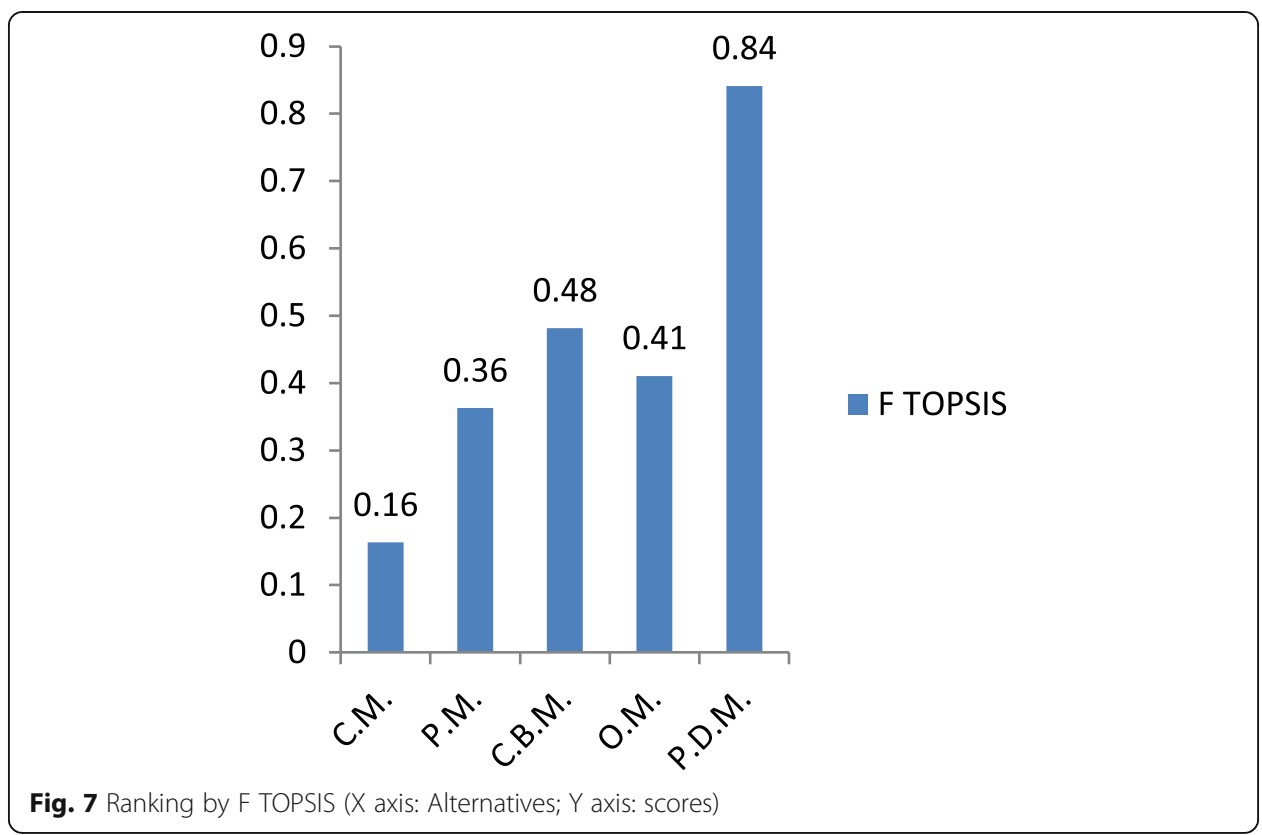

the methods value for COS for PDM is highest. In other words from all the three methods PDM has been ranked number one (01).

c) It can be concluded that predictive maintenance is the optimum maintenance for the SGU of coal fired thermal power plant, as it has highest COS in all three methods used.

d) $\mathrm{SCR}_{1}, \mathrm{SCR}_{2}, \mathrm{SCR}_{3}, \mathrm{SCR}_{7}, \mathrm{SCR}_{8}, \mathrm{SCR}_{9}$ are pertinent criteria for present study

e) The research findings have good scope of implementation, if MADM and graphical findings are adopted by management of organization.

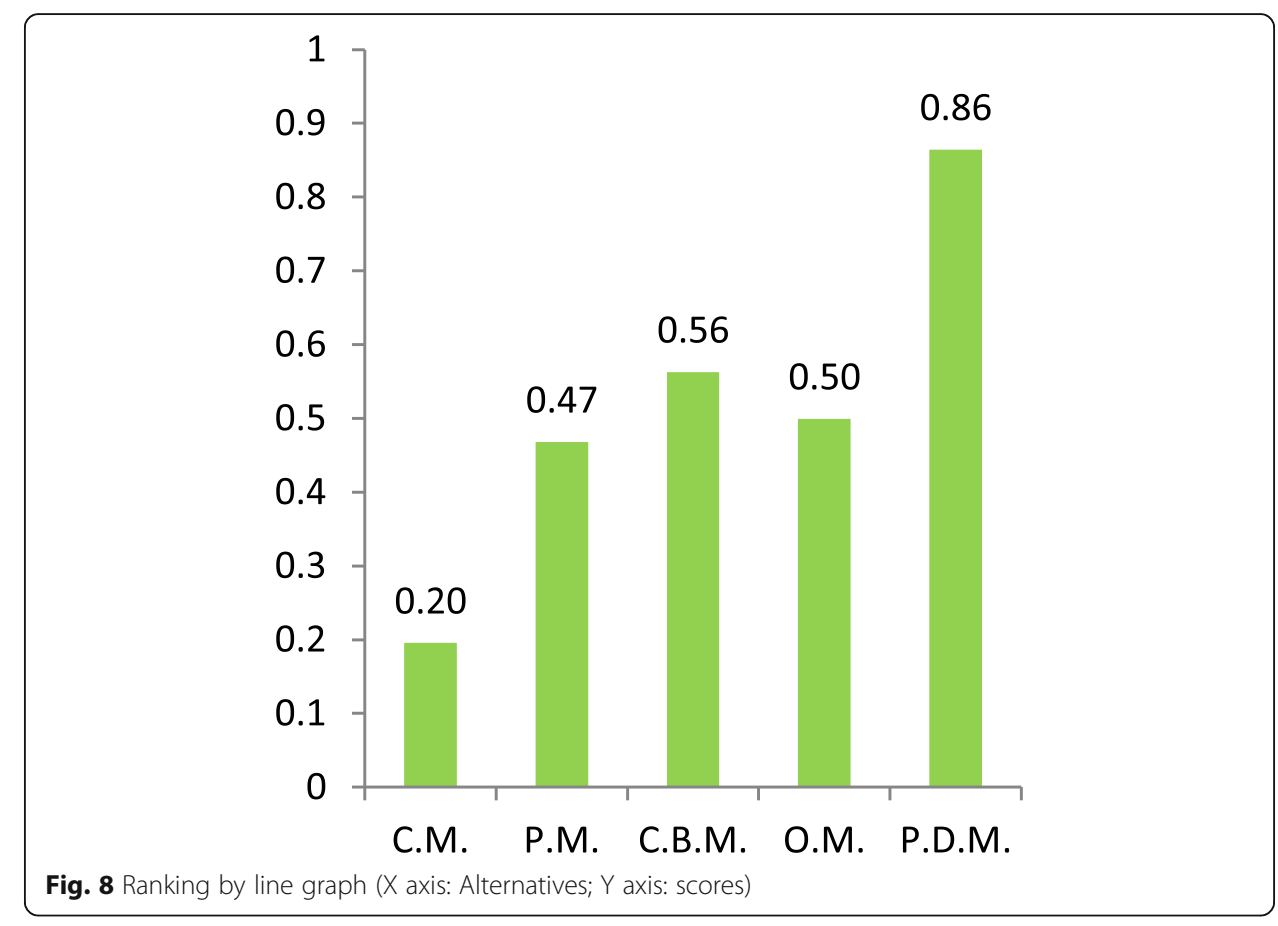




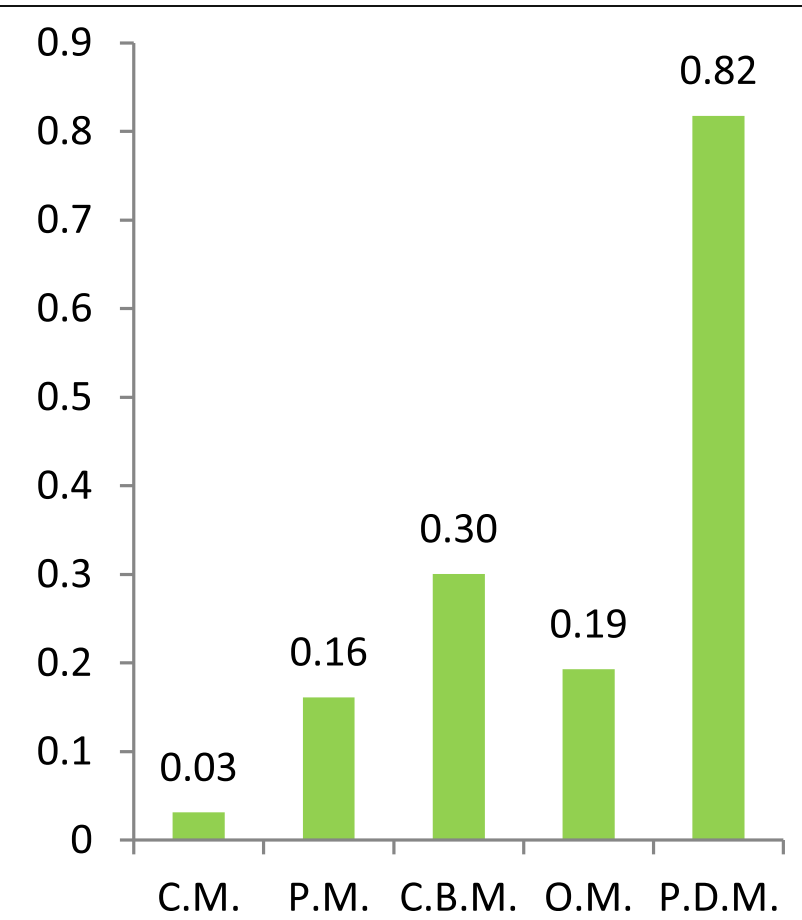

Fig. 9 Ranking by spider graph ( $X$ axis: Alternatives; $Y$ axis: scores)

The case study findings are suggested to the management of power plant for future course of action. Inferences from personal discussion with management were solely dependent on experience and expertise of person concerned. The inferences were mostly subjective and rarely quantitative. Interpretation on vagueness can vary from person to person. The author has tried to remove this vagueness, uncertainties in

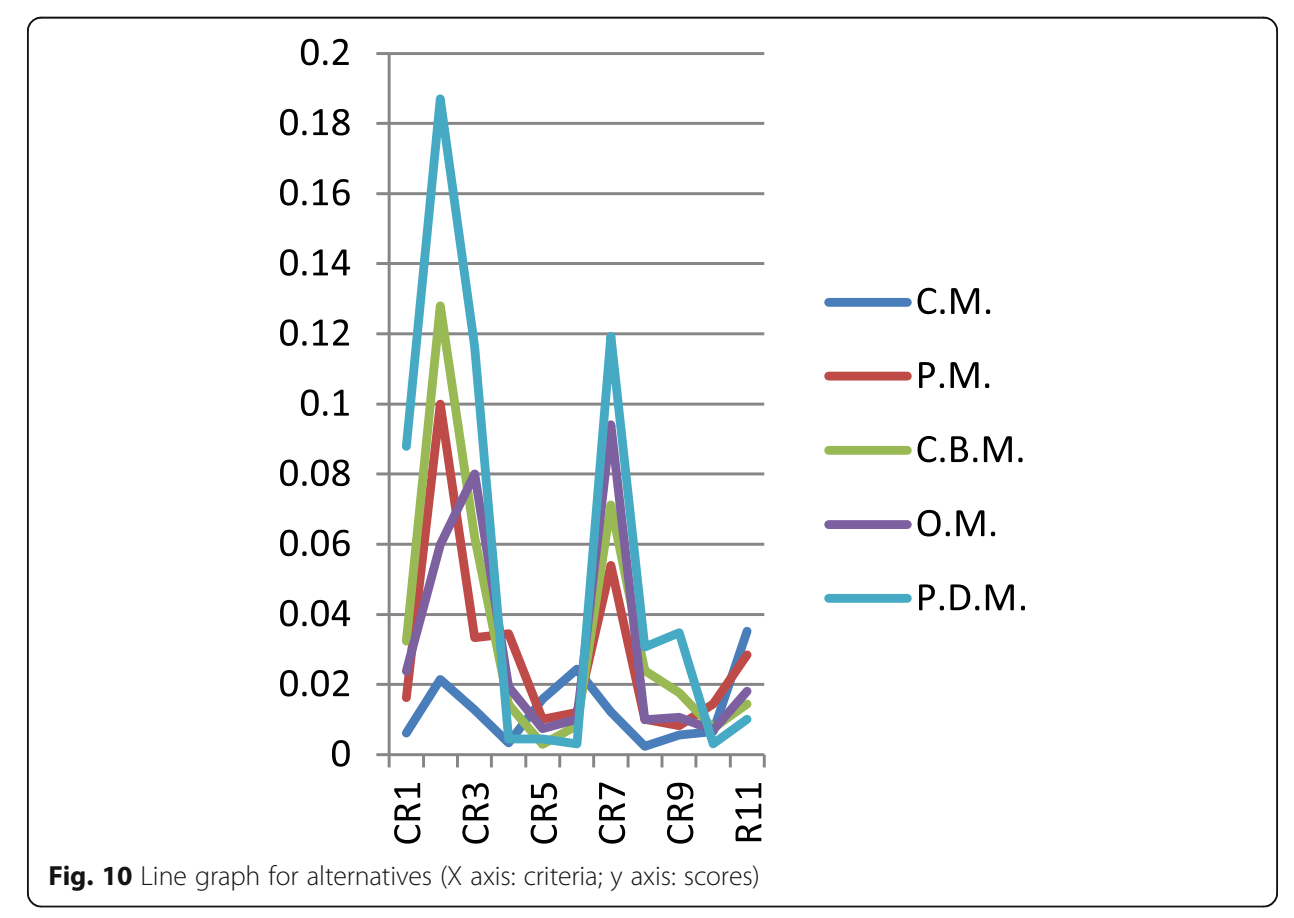




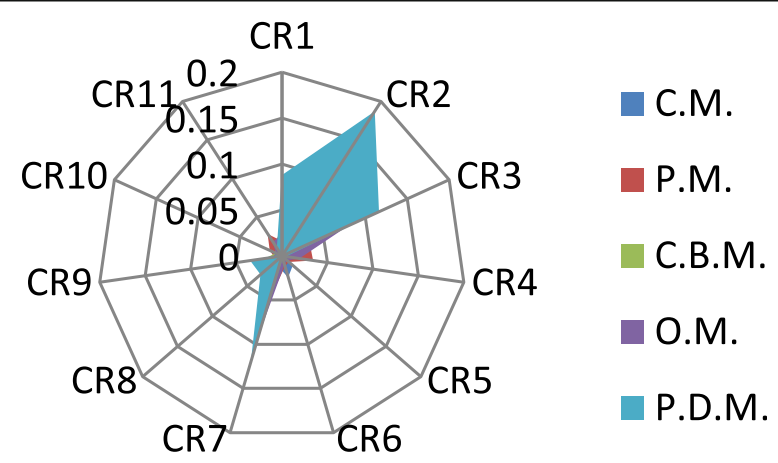

Fig. 11 Spider graph for alternatives

judgement using TFN. The authenticity of records available in maintenance department was hard to check.

Present research has a lot of scope for future research like:

a) This research can be undertaken over other process industries like paper mill, fertilizer plants etc.

b) Within the Power plant, research can be further extended over other vital equipment.

c) For macro general overview, this study can be replicated over several other plants and common conclusion can be drawn.

d) The maintenance decision results of the present study can be compared with other MCDM approaches such as fuzzy DEMETAL, Fuzzy VIKOR, Fuzzy Electra, Fuzzy PROMETHEE, etc.

e) The integrated approach with other MADM techniques e.g. Fuzzy AHP-VIKOR etc., can be compared with the present results.

f) For future research more criteria and sub-criteria can be added under the MCDM framework and determine their influence on outcome.

\section{Methodology}

The proposed integrated model of (i) Fuzzy AHP, (ii) Fuzzy Topsis (iii) Fuzzy graphical methods have been used for ranking of maintenance alternatives. The weights are computed by using fuzzy synthetic extent analysis method.

\section{Purpose}

The purpose of study is to (i) Generate a reliable, exhaustive database for maintenance strategy selection based on agile maintenance attributes. (ii) Propose an integrated model for selection of maintenance strategy using generated database. (iii) To prioritize attributes, so that more focus can be given to pertinent attributes.

\section{Findings}

After research review and personnel discussions with plant management database of agile maintenance attributes was generated. The proposed integrated model was 
applied to SGU of thermal power plant. There appears good amount of synergy between Fuzzy AHP, Fuzzy TOPSIS and Fuzzy graphical method of ranking respectively. PDM has been ranked first by all the applying all the above stated methods. The subcriteria (SCR) have been prioritized using graphical method of line and spider diagram respectively. Personal safety $\left(\mathrm{SCR}_{2}\right)$, Equipment safety $\left(\mathrm{SCR}_{3}\right)$, Environment $\left(\mathrm{SCR}_{1}\right)$, Production loss $\left(\mathrm{SCR}_{7}\right)$, Spare part inventory $\left(\mathrm{SCR}_{8}\right)$ and fault identification $\left(\mathrm{SCR}_{9}\right)$ have been found out pertinent attributes.

\title{
Implications
}

This research can be undertaken over other process industries like paper mill, fertilizer plants, sugar plant etc. Within the thermal power plant, research can be further extended over other vital equipment like pumps, fans, condenser tubes, turbine blades, etc. For macro general overview, this study can be replicated over several other plants and common conclusion can be drawn.

\section{Practical implication}

The research findings have good scope of implementation, if fuzzy multi attribute decision making (MADM) and fuzzy graphical findings are adopted by management of organization.

\section{Originality}

The novelty of research work is selection of strategy based on agile maintenance attributes and use of integrated fuzzy AHP, fuzzy TOPSIS and fuzzy graphical approaches in decision making.

\section{Additional file}

Additional file 1: Annexure A. (DOCX $24 \mathrm{~kb})$

\begin{abstract}
Abbreviation
AGM: Agile Manufacturing; AHP: Analytical Hierarchical Process; BHEL: Bharat Heavy Electrical Limited, India; CBM: Condition based maintenance; CM: Corrective Maintenance; COS: Coefficient of similarity; DM: De-mineralized; FAHP: Fuzzy Analytical Hierarchical; FD: Forced Draught; FDM: Fuzzy decision matrix; FIAS: Fuzzy anti ideal solution decision matrix; FIS: Fuzzy ideal solution; GMA: Graphical Method Approach; ID: Induced Draft; MADM: Multi Attribute decision making; MISO: Multi input single output; MTTF: Mean time to fail; MTTR: Mean time to repair; NFDM: Normalized Fuzzy decision matrix; OP: Opportunistic maintenance by similarity to ideal solution; PDM: Predictive maintenance; PM: Preventive maintenance; SCR: Sub Criteria; SGU: Steam generating unit; TFN: Triangular fuzzy number; TMF: Triangular membership function; TOPSIS: Technique for order preference; TTT: Total time on test Process; WNFDM: Weighted normalized Fuzzy
\end{abstract}

\section{Acknowledgements}

The author acknowledges help and valuable suggestion given by Er. Rajinder Choudhary and other maintenance staff at PTPS, India.

\section{Authors' contributions}

PS is PhD scholar under guidance of DK, Professor, Department of ME, National Institute of Technology, Kurukshetra (India) and VPA, Visiting Professor, Department of ME, TIET, Thapar University, Patiala (India). DK and VPA has guided corresponding author in formulation of problem and application of research methods. All authors read and approved the final manuscript. 


\section{Author details}

${ }^{1}$ Department of Mechanical Engineering, NIT, Kurukshetra, Haryana 136119, India. ${ }^{2}$ Department of Mechanical Engineering, ASET, AUUP, Noida, UP 201303, India. ${ }^{3}$ Department of Mechanical Engineering, Thapar University, Patiala, Punjab 147001, India.

Received: 25 October 2016 Accepted: 5 September 2017

Published online: 03 October 2017

\section{References}

1. Al-Najjar B (2012) On a graphical method for the selection of a maintenance technique

2. Al-Najjar B (2007) The lack of maintenance and not maintenance which costs: A model to describe and quantify the impact of vibration-based maintenance on company's business. Int J Prod Econ 107(1):260-273

3. Al-Najjar B, Alsyouff I (2003) Selecting the most efficient maintenance approach using fuzzy multiple criteria decision making. Int J Prod Econ 84(4):85-100

4. Azadivar F, Shu V (1999) Maintenance policy selection for JIT production system. Int J Prod Res 37(6):3725-3738

5. Bengtsson, M (2004) Condition Based Maintenance System Technology-Where is Development Heading? In: Proceeding of 17th European Maintenance Congress, Spain

6. Bevilacqua M, Braglia M (2000) The analytic hierarchy process applied to maintenance strategy selection. Reliab Eng Syst Saf 70(1):71-83

7. Bhangale PP, Agrawal VP, Saha SK (2004) Attribute based specification, comparison and selection of a robot. Mech Mach Theory 39(12):1345-1366

8. Byington, C, Roemer, MJ, Galie, T: Prognostic enhancement to diagnostic systems improved condition based maintenance. Proceedings of IEEE Aerospace Conference, 6, Big Sky, USA, March 9-16, 2815-2824 (2002)

9. Chan FTS, Kumar N, Tiwari MK, HCW L, Choy KL (2008) Global supplier selection: A fuzzy-AHP approach. Int J Prod Econ 46(14):3825-3857

10. Chan F T S, Lau H C W, Ip R W L, Chan H K, \& Kong S (2005) Implementation of total productive maintenance: A case study. International Journal of Production Economics 95(1): 71-94

11. Chang DY (1992) Extent analysis and synthetic decision. Optim Tech Appl 1(1):352-355

12. Ding SH, Kamaruddin S, Abdul Azid I (2014) Maintenance policy selection model-a case study in the palm oil industry. J Manuf Technol Manag 25(3):415-435

13. Hwang CL, Yoon K (1981) Methods for multiple attribute decision making. In: Multiple attribute decision making Springer, Berlin / Heidelberg p 58-191

14. Ilangkumaran M, Kumanan S (2009) Selection of maintenance policy for textile industry using hybrid multi-criteria decision making approach. J Manuf Technol Manage 20(7):1009-1022

15. Khorasani, O, Bafruei, MK (2011) A fuzzy AHP approach for evaluating and selecting supplier in Pharmaceutica Industry. Int J Acad Res 3(1):346-352

16. Kidd, PT: Agile Manufacturing: Forging New Frontiers. Wokingham, England. Reading, Massachussets, Addison-Wesley (1994)

17. Mann L, Saxena A, Knapp GM (1995) Statistical-based or condition-based preventive maintenance. J Qual Maint Eng 1(1):46-59

18. Mikhailov L, Tsvetinov P (2004) Evaluation of services using a fuzzy analytical hierarchy Process. Appl Soft Comput 5(1):25-33

19. Mishra R (2014) Structural modelling and analysis of world-class maintenance system: a graph theoretic approach. Int J Process Manage Benchmark 4(1):69-88

20. Mobley RK (2002): An introduction to predictive maintenance. Butterworth-Heinemann, Oxford

21. Okumura S, Okino N (2003) A maintenance policy selection method for a single unit item in each workstation composing a FMS with CBM optimisation. Int J COMADEM 6(2):3-9

22. Panchal D, Kumar D (2016) Stochastic behaviour analysis of power generating unit in thermal power plant using fuzzy methodology. Opsearch 53(1):16-40

23. Pourjavad E, Shirouyehzad H, Shahin A (2013) Selecting maintenance strategy in mining industry by analytic network process and TOPSIS. Int J Industr Syst Eng 15(2):171-192

24. Rao PV, Baral SS (2011) Attribute based specification, comparison and selection of feed stock for anaerobic digestion using MADM approach. J Hazard Mater 186(2):2009-2016

25. Saaty TL (1980) The Analytic Hierarchy Process: Planning, Priority Setting, Resource Allocations. Mc-Graw Hill, London

26. Shahin A, Shirouyehzad H, Pourjavad E (2012) Optimum maintenance strategy: a case study in the mining industry. Int J Serv Operat Manage 12(3):368-386

27. Shahin A, Ghofrani IN, Tabatabaei NA (2013) Determining appropriate maintenance strategy based on decision making grid, Sigma level, and process capability index with a case study in a steel company. Int J Appl Manag Sci 5(3):265-280

28. Sharma RK, Kumar D, Kumar P (2005) FLM to select suitable maintenance strategy in process industry using Miso model. J Qual Maint Eng 11(4):359-374

29. Shyjith K, liangkumaran M, Kumanan S (2008) Multi-criteria decision-making approach to evaluate optimum maintenance strategy in textile industry. J Qual Maint Eng 14(4):375-386

30. Srivastava, P, Khanduja, D, Agrawal, VP (2014) Modelling of Agile Manufacturing System. Proceeding of ICAM-2014, Rochester, USA, May 28-30, 86-103

31. Srivastava, P, Khanduja, D, Agrawal, VP: Integrating Agile Thinking into Maintenance Strategy performance Analysis. Int J Proc Manage Benchmark, x(x),xx. (in press)

32. Swanson $L$ (2001) Linking maintenance strategies to performance. Int J Product Econ 70(3):237-244

33. Triantaphyllou E, Kovalerchuk B, Mann L, Kna GM (1997) Determining the most important criteria in maintenance decision making. J Qual Maint Eng 3(1):16-28 
34. Waeyenbergh G, Pintelon L (2002) A framework for maintenance concept development. Int J Product Res 77:299-313

35. Wang H (2002) A survey of maintenance policies of deteriorating systems. Eur J Operat Res 139(3):469-489

36. Wang L, Chu J, Wu J (2007) Selection of optimum maintenance strategy based on a fuzzy analytic hierarchy Process. Int J Product Econ 107(1):151-163

37. Wireman T (1990) World Class Maintenance Management. Industrial Press, Industrial Press, New York

38. Wongmongkolrits $S$, Rassamuthes B (2011) The heuristics of effective maintenance policy under the given availability. Int J Collab Enterp 2(4):251-262

39. Zadeh $L$ (1975) The concept of a linguistic variable and its application to approximate reasoning. Inform Sci 8(3):199-249

40. Zuo J (1991) Multiple Objective Decision Analysis. Zhejiang University Press, Hangzhou.

Submit your manuscript to a SpringerOpen ${ }^{\circ}$ journal and benefit from:

- Convenient online submission

- Rigorous peer review

- Open access: articles freely available online

- High visibility within the field

- Retaining the copyright to your article

Submit your next manuscript at $>$ springeropen.com 